\title{
Modelling migration from paper into a food simulant
}

\author{
Maria de Fátima Poças ${ }^{\mathrm{a}, *}$, Jorge C. Oliveira ${ }^{\mathrm{b}}$, Joel R. Pereira ${ }^{\mathrm{a}}$, Rainer Brandsch ${ }^{\mathrm{c}}$, Timothy $\operatorname{Hogg}^{\mathrm{d}}$ \\ a Packaging Department, Biotechnology College, Portuguese Catholic University, Rua Dr. António Bernardino de Almeida, $4200-072$ Porto, Portugal \\ ${ }^{\mathrm{b}}$ Department of Process \& Chemical Engineering, Food Science Building, University College Cork, Ireland \\ ${ }^{\mathrm{c}}$ MDCTec Ltd., ZN Gilching, UntereLaeng 8c, 82205 Gilching, Germany \\ ${ }^{\mathrm{d}} \mathrm{CBQF}$, Biotechnology College, Portuguese Catholic University, Rua Dr. António Bernardino de Almeida, 4200-072 Porto, Portugal
}

Keywords:

Migration

Migration modelling

Paper

Board

Packaging

Mathematical model

Tenax $^{\circledR}$

Phthalates

Recycling

\begin{abstract}
A B S T R A C T
The migration of components from paper into Tenax ${ }^{\circledR}$ was studied to determine the influence of molecular size and chemical character of the migrant and the influence of paper characteristics in the migration process. The Weibull model was applied because Fick's 2nd law of diffusion gave poor fits in some cases. The migration pattern depended on the migrants molecular size and was independent of temperature in the studied range. The migration rate decreased with the migrant molecular size. The influence of the migrants character (polarity and vapour pressure) on the migration behaviour was also studied: nonpolar migrants with high vapour pressure presented low relative migration values and polar migrants presented high values of relative migration. Results indicated that the apparent partition coefficient between paper and the simulant Tenax ${ }^{\circledR}$ increased with the migrant vapour pressure and with both the paper grammage and the recycled pulp content.
\end{abstract}

\section{Introduction}

Packaging plays an essential role in assuring quality and safety of food, protecting, containing and preserving it through the supply chain. Paper and board are used as primary, secondary and tertiary (transport) packaging. They are usually perceived by consumers as safe and healthy due to the natural origin from wood. However, chemical hazards from potential migrants must be considered such as additives intentionally added during manufacture to improve paper and board characteristics (García-Gómez, Carbonell, \& Tarazona, 2004) and unintentionally added substances due to incorporation of recycled pulp (Poças \& Hogg, 2007). When functioning as primary packaging, paper and board are most often used in contact with dry solid foods. In this situation substances present in the paper and board can migrate into the food by direct contact (Fig. 1a) or indirectly through the gas phase between the material surface and the food surface (Fig. 1b). Migration can occur not only

\footnotetext{
* Corresponding author.
}

E-mail addresses: mfpocas@esb.ucp.pt (M.F. Poças),jmcoliveira@gmail.com (J.C. Oliveira), jrpereira@esb.ucp.pt (J.R. Pereira), Rainer.brandsch@mdctec.net (R. Brandsch), tahogg@esb.ucp.pt (T. Hogg). from the primary packaging material, but also from the secondary system, typically a paperboard or corrugated board box although not anticipated to come into direct contact with the food: volatile and semi-volatile organic substances in this type of material may be transferred through the inner packaging into the food. Transfer of substances present in the external surface not intended to contact with food, such as components from printing inks or lacquers, may also occur: through the cellulose fibre matrix into the food (Fig. 1c) or by set-off when folding cartons are stacked or reels are stored (Bradley et al., 2005; Johns, Jickells, Read, Gramshaw, \& Castle, 1996). The set-off effect refers to the interaction process in the course of printing, storage or use of a food package where the non-printed surface of packages comes into contact with the printed surface and, consequently, printing ink components can migrate into the food contact layer of the packaging and from there to the packed food (Zhang, Noonan, \& Begley, 2008). A fraction of the substances is most likely transferred also from the paper matrix to the surroundings (Fig. 1d).

Although a considerable amount of work has been devoted to identify and quantify the potential migrants in paper and paperboard, particularly contaminants with origin in recovered fibre, much less effort has been dedicated to understand the factors that influence the rate and the level of migration from paper and to 
c)

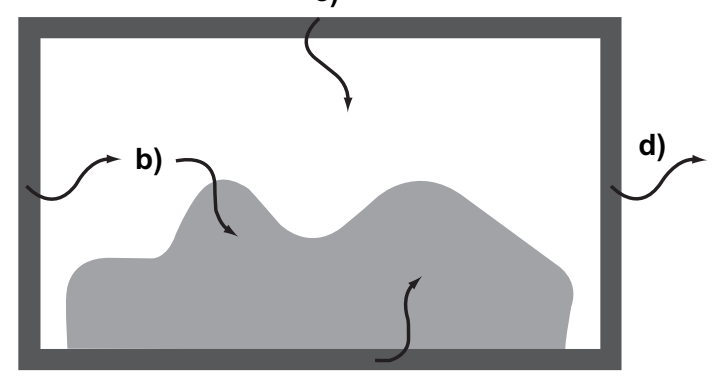

a)

Fig. 1. Transfer mechanisms in paper (board): a) from the fibre matrix by direct contact; b) from the fibre matrix by indirect contact; c) from outer surface through the fibre matrix; and d) from the fibre matrix to the surrounding environment.

develop mathematical models to describe the process. The objectives of this work were (i) to determine which characteristics of the migrant and of the paper affect the migration into a solid simulant and (ii) to verify the applicability of the Weibull model to describe the migration of components from paper and borad.

Two sets of migrants were selected. One was composed of migrants with similar structure but with different molecular weight. Phthalates are among the contaminants most often present in cellulosic packaging, and therefore, understanding their migration behaviour is of utmost interest. A series of di-ester phthalates was selected. The second set of migrants studied was composed by substances with similar molecular weight but with different chemical functional groups, corresponding to different polarity. Some of the substances considered in this case are also among the common contaminants of recovered fibre. Paper was spiked with the migrants and brought into contact with the solid simulant Tenax ${ }^{\circledR}$. The concentration of the migrants in the solid simulant was determined for different times of contact. Tenax ${ }^{\circledR}$ was selected as simulant because it is the most referred in literature and recommended to mimic the contact with dry solid food. Much of the work published to date considered high temperatures, such as $100{ }^{\circ} \mathrm{C}$ and above, in order to obtain experimental data faster. The studies were conducted at low temperatures of $8-40{ }^{\circ} \mathrm{C}$ which covers storage under refrigeration and room temperature conditions, as well as temperature accelerated conditions for conducting migration tests for compliance assessment of packages used at room temperature. The level of migration of one specific phthalate into different papers was determined to evaluate the effect of grammage and recycled pulp content. While some of the published work determined the partition coefficient between paper and air, in the present case the partition coefficients between paper and Tenax ${ }^{\circledR}$ were determined. The Weibull model, was applied to describe the migration of phthalates into Tenax ${ }^{\circledR}$ and compared with the classical diffusion model based on Fick's 2nd law.

\section{Mechanisms of mass transfer and factors affecting migration}

The mechanism of migration from fibre-based materials is different from the one occurring in plastics. Paper and board materials are heterogeneous, open and porous structures consisting of cellulosic fibres and air pores. The mobility through the paper therefore comprises adsorption/desorption of the migrant on the fibre, transfer across the fibre and diffusion in the air pores. Diffusion through a gas phase is usually much faster than diffusion in liquid or solid phases. Thus, this step of the overall mechanism is not expected to play a role in limiting the rate of migration.
In order to be transferred through the gas phase, particularly in indirect migration, the migrant must exhibit a certain propensity to volatilise, i.e. it must possess a certain vapour pressure at the temperature of use (lower than its boiling point). The chemical character of the cellulosic fibres is expected to be important for the interaction with the substance: the cellulosic fibres are very hydrophilic and largely non-ionic and, on the other hand, the lignin fraction has aromatic phenolic units with hydrophilic and hydrophobic domains that are anionic. This gives an overall negative charge to the surface of paper due to carboxyl and the hydroxyl groups of the lignin (Castle, 2004), influencing the migrant behaviour, particularly the vapour pressure and partitioning of the substance between fibre and air.

Several factors may be anticipated to determine the level and the rate of migration (Castle, 2004; Mariani, Chiacchierini, \& Gesumundo, 1999; Triantafyllou, Akrida-Demertzi, \& Demertzis, 2005; Zhang et al., 2008):

- Type of contact (direct or indirect);

- Food or food simulant;

- Type of paper (characteristics such as thickness, porosity, pulp content in lignin and in recycled fibre);

- The chemical nature (vapour pressure, polarity, molecular size and structure, etc.) and the initial concentration of the migrant in the paper;

- Time and temperature of contact.

There is evidence that migration level is higher when there is direct contact with food (Anderson \& Castle, 2003; Johns et al., 1996). Furthermore, Mariani et al. (1999) suggested that the influence of food is noticed when there is a direct contact-type mechanism. When there is a head-space in the package over the product, the foods tested show similar migration patterns and final migrant concentrations, regardless of the foods characteristics. In indirect contact, the presence of an additional layer of packaging between the outer secondary packaging and the inner primary packaging was shown to reduce transfer of migrant into food and hence to increase the lag time observed for the transfer of migrant from packaging to food (Jickells, Poulin, Mountfort, \& Fernàndez-Ocaña, 2005).

Simulants for migration studies from paper and board must be solid adsorbents to mimic the contact with dry foods. Tenax ${ }^{\circledR}$ (modified polyphenylene oxide) is the most commonly referred simulant and it is already foreseen in the European legislation for testing migration at high temperatures simulating fatty foods. The migration behaviour of components from paper into Tenax ${ }^{\circledR}$ has been compared to the migration into real dry foods: semolina pasta, sugar, flour, milk powder and rice (Aurela, Kulmala, \& Soderhjelm, 1999; Mariani et al., 1999; Nerín, Contín, \& Asensio, 2007; Triantafyllou, Akrida-Demertzi, \& Demertzis, 2007). Results obtained in different studies suggest that equilibrium concentration in this simulant is often higher than the equilibrium concentration found in the actual food, thus indicating that results obtained with the simulant have a safe margin. However, in other cases, particularly in high temperature testing, results obtained with Tenax ${ }^{\circledR}$ can be lower than those with real food. Poropak ${ }^{\circledR}$ and a semisolid mixture (diatomaceous earth, olive oil and water) are other simulants referred in literature (Nerín \& Acosta, 2002; Summerfield \& Cooper, 2001). The fat content of the food was found to contribute to higher migration levels, especially at high temperatures (Triantafyllou et al., 2007). A possible explanation was the eventual melting at the high testing temperature of the non-surface fat which came into intimate contact with the paper.

To contact with liquid food or solid food with high moisture or free fat contents, paper and board must be coated or laminated with 
plastic. These plastic layers may potentially represent a functional barrier to migration from substances present in the paper or paperboard. Polyolefins such as PE and PP are considered poor functional barriers. Migration rates through a functional barrier depend on the thickness of the plastic layer, on the solubility of the substance in the functional barrier, i.e. partitioning between paper or board and the plastic layer and on temperature (Choi, Jitsunari, Asakawa, \& sun Lee, 2005; Song, Begley, Paquette, \& Komolprasert, 2003). The amount of substances transferred increases with the initial concentration in the paperboard (Song et al., 2003).

The paper grammage and thickness was found to have a significant effect on migration rate: low grammage resulted in faster migration rate (Castle, 2004; Nerín et al., 2007). The percentage of recycled pulp was found to not affect directly the rate of migration (Castle, 2004; Nerín et al., 2007). Triantafyllou, Akrida-Demertzi, and Demertzis (2002, 2007) found higher migration values (as percentage of migration relative to initial amount) for paper tissue than for fluting paper. However, these results are potentially affected by both the percentage recycled pulp and grammar that were considerably different for these papers. Data from different works suggest that the effect of recycled pulp content is not very clear. Castle (2004) reported no significant differences between the migration levels from paper with different compositions and data from Nerín et al. (2007) showed opposite trends to migration of diisopropylnaphthalene (DIPN) and diisobutyl phthalate (DiBP) from papers with similar grammage and different contents in recycled pulp. DiBP presented higher migration values from the paper with $100 \%$ recycled pulp while DIPN presented higher migration values from the paper with $10-30 \%$ recycled pulp.

The nature of the migrant is expected to play a major role on the migration process. Johns et al. (1996) found that the volatility (boiling point) greatly influences the amount of substance transferred during long term storage and the migration behaviour of the substance when the food is heated in the package. Substances with higher volatility tend to migrate more rapidly and at higher levels (Jickells et al., 2005). It was postulated that there may be a cut-off threshold in terms of volatility and gas phase transfer, such that substances with volatilities lower than the cut-off threshold will not transfer from the secondary packaging to foods stored at ambient temperature. Substances with volatilities higher than the threshold may transfer depending on the storage time, the nature of the primary packaging and the concentration of substance in the secondary packaging (Jickells et al., 2005).

The partition coefficient of substances between the paper or paperboard and the air is a key parameter for prediction of migration into the food. It depends on the boiling point of the migrant and its chemical structure, as well as on the type of paper, and increases with temperature (Triantafyllou et al., 2005). Experiments showed that migrants are not totally transferred to the food simulant (maximum migration does not reach $100 \%$ ) which means that the affinity of the compounds for the matrix is such that the migration is more difficult than expected (Nerín et al., 2007). The more volatile substances partitioned more readily in the air at any temperature, presenting a lower partition coefficient (Triantafyllou et al., 2002, 2005). However, data seem to indicate that there is not a linear relationship between the boiling point of a substance and its partitioning behaviour (Haack \& Franz, 2000; Jickells et al., 2005). The retention behaviour of the substance in the paper matrix depends also on its interaction with fibres surface and, as mentioned before, the cellulose fibres have an overall negative charge due to carboxyl groups from the carbohydrates and the hydroxyl groups of the lignins. Thus, substances rich in electrons, such as naphthalene, tend to be repelled and are not retained by the fibre. As a consequence, these substances are less absorbed by the paper. On the contrary, DBP and methyl stearate, with higher boiling points, partitioned strongly into the condensed phase of the paper. For the more polar surrogates, such as acetophenone, higher absorption to the paper than expected according to its boiling point, was observed due to high affinity of substances for the fibres surface (Triantafyllou et al., 2005). Thus not only the boiling point but also the polarity and the affinity with the paper fibres are key factors in determining partition between paper and air.

The final migration value of DIPN (concentration in food) was found to be proportional to the initial concentration of the substance in the paper (Mariani et al., 1999). The adsorption isotherms (relationship between the concentration of substance in the paper and in the surrounding air) were found to present a typical Langmuir shape, reaching asymptotically an upper limit due to saturation of the cellulosic phase (Triantafyllou et al., 2005). The linear range of the isotherm covered the range of migrants' concentration that was found to occur as contaminants of paper and board in practice. Because the coefficient of partition is the slope of the adsorption isotherm, it is approximately constant in this range (Castle, 2004).

The temperature was found to influence the rate and the level of migration. The higher the temperature the faster the equilibrium is reached (Castle, 2004; Triantafyllou et al., 2005). Data seem to indicate a trend with a linear correlation between the log of time for equilibrium and the inverse of temperature. The partition coefficient between paper and air decreased with temperature (Haack \& Franz, 2000; Triantafyllou et al., 2005). This means that when the temperature increases, the amount adsorbed in the paper decreases and the migration level tends to increase.

\section{Mathematical models}

The development of predictive migration models for cellulosic materials in contact with food has not been often focused in published studies probability because of the difficulties associated with the non homogeneity of fibre-based materials (Aurela \& Ketoja, 2002). A few works can be mentioned restricted to correlating migrant content in the paper and the final values for direct contact migration (Mariani et al., 1999) and comparison of mass fraction of migrant under different pack formats and storage conditions (Anderson \& Castle, 2003).

Aurela and Ketoja (2002) compared experimental results from transfer of certain volatiles through paper with computer simulations in which the fibre network was simulated by a virtual network of paper fibres. By varying the fraction of fibres with different dimensions and flexibility, the virtual fibre network presented a porosity matching the experimental one. The transfer of volatiles in the fibre was simulated by a random walk model that does not consider the diffusion along the fibres nor the absorption by the fibres (10 000 walkers). An effective diffusion coefficient was calculated with the paper porosity and the diffusion coefficient in the air.

Castle (2004) applied the classical diffusion models based on Fick's 2nd law that may be represented by equation (1) for the case where migration is controlled by diffusion in the packaging material.

$$
\begin{aligned}
& \frac{C(t)}{C_{\infty}}=1-\sum_{n=1}^{\infty} \frac{2 \alpha(1+\alpha)}{1+\alpha+\alpha^{2} q_{n}^{2}} \exp \left(-\frac{q_{n}^{2}}{L^{2}} D^{P} t\right) \\
& \alpha=\frac{V_{F} / V_{P}}{K_{F}^{P}}
\end{aligned}
$$

and $q_{n}$ are the non-zero positive roots of:

$\tan \left(q_{n}\right)=-\alpha q_{n}$ 
The diffusion coefficient was estimated with equation (4). The $A_{P}$ parameter ranged from 7 to 12 for the migration from different papers into Tenax ${ }^{\circledR}$.

$D_{A}^{P}=10^{4} \exp \left(A_{p}-C_{1} M_{w}^{2 / 3}+C_{2} M_{w}-C_{3} / T\right) \mathrm{cm}^{3} / \mathrm{s}$

However, it has been suggested that assuming a one-dimensional diffusion process has limitations in describing transfer in papers with low porosities and low thicknesses. Hellén, Ketoja, Niskanen, and Alava (2002) studied the problem of absorption of a component by paper from a solution of constant concentration. It was found that there was a threshold grammage for the validity of the diffusion model that increased as the paper porosity decreased. Therefore, the diffusion model should not be applied to greaseproof and glassine papers that have typically low porosity and low thickness (Hellén et al., 2002).

A kinetic model based on the Weibull distribution function (5) was previously applied to describe migration from plastics additives in comparison with the models based on Fick's 2nd law (Poças, Oliveira, Brandsch, \& Hogg, in press).

$\frac{C(t)}{C_{\infty}}=1-\exp \left[-\left(\frac{t}{\tau}\right)^{\beta}\right]$

The model has two parameters: $\tau$, the system time constant or the scale parameter, associated to the process rate and related to the diffusion coefficient and the material thickness, and $\beta$ the shape parameter, related to the initial rate of the process, quantifying the pattern of curvature observed (Poças et al., in press). This model was found to be simple and flexible in describing several mass transfer processes within food engineering area and in food packaging systems, in cases where diffusion theories could not fully explain the mass transfer process.

\section{Materials and methods}

\subsection{Paper samples}

Paper kraft liner with different grammage and recycled pulp content was provided by Portucel Viana, S.A. (Viana, Portugal). The paper was composed of ca $80 \%$ pine and $20 \%$ eucalyptus fibre. The pulp was prepared in a Valley-type laboratory beater and the sheets were pressed in a manual hydraulic press. Table 1 presents the characteristics of the papers used. Papers 1-4 were used in the experiment to determine factors affecting partition behaviour between paper and solid simulant; paper 5 was used in the experiment with phthalates of different size and in the experiment with different migrants.

\subsection{Chemicals}

Tables 2 and 3 show, respectively, some characteristics of the phthalates and of the other migrants used in the experiments. All phthalates were GC grade (Fluka, Sigma and Riedel-de Häen). Deuterated di-hexyl phthalate (d-DHP) (Riedel-de Häen) was used as internal standard in the phthalates experiment and BHT (Merk)

Table 1

Characteristics of the papers $(\mu \pm \sigma)$.

\begin{tabular}{llllll}
\hline Paper & \multicolumn{1}{l}{1} & \multicolumn{1}{l}{ 2 } & \multicolumn{1}{l}{3} & \multicolumn{1}{l}{4} & 5 \\
\hline Grammage, g/m2 & $82 \pm 1$ & $179 \pm 3$ & $87 \pm 1$ & $181 \pm 6$ & $146 \pm 2$ \\
Thickness, $\mu \mathrm{m}$ & $134 \pm 6$ & $257 \pm 7$ & $153 \pm 7$ & $287 \pm 2$ & $230 \pm 8$ \\
Recycled pulp, \% & \multicolumn{1}{l|}{20} & 20 & 80 & 80 & 25 \\
\hline
\end{tabular}

Table 2

Physical characteristics of the phthalates.

\begin{tabular}{llllll}
\hline & DMP & DEP & DBP & DHP & DOP \\
\hline $\mathrm{N}^{\circ}$ CAS & $131-11-3$ & $84-66-2$ & $84-74-2$ & $84-75-3$ & $117-84-0$ \\
$\mathrm{Mw}$ & 194.2 & 222.24 & 278.3 & 334.46 & 390.5 \\
$\mathrm{Bp},{ }^{\circ} \mathrm{C}$ & 284 & 295 & 340 & 350 & 416 \\
$\rho$ & 1.19 & 1.12 & 1.05 & 1.05 & 0.98 \\
$\log P o / w$ & 1.48 & 2.51 & 4.63 & 6.67 & 8.3 \\
\hline
\end{tabular}

was used as internal standard in the other migrants case. Tenax ${ }^{\circledR}$ (Modified polyphenylene oxide, Quadrex, Weybridge-UK) 60/80 mesh, $0.29 \mathrm{~g} / \mathrm{cm}^{3}$ was used as solid simulant. It was cleaned up prior to use by extraction with diethyl ether. Hexane used for paper and Tenax ${ }^{\circledR}$ extractions was GC grade (Fluka).

\subsection{Spiking the paper}

The paper to be tested was spiked with the migrants indirectly through the contact with blotting paper previously spiked with the migrants. The blotting paper had a grammage of $36 \mathrm{~g} / \mathrm{m}^{2}$ and a water capillary raise of $107 \mathrm{~mm}$ (Klemm method). The blotting paper was spiked by immersion in two solutions containing the migrants, respectively at concentrations of ca $300 \mathrm{mg} / \mathrm{l}$ of each phthalates. After $2 \mathrm{~h}$ the blotting paper was removed and allowed to dry. Each piece of paper to be tested was placed in a sandwich of blotting paper, wrapped around in aluminium foil and allowed to set for two days.

\subsection{Migration experiments}

Ca $1 \mathrm{~g}$ of Tenax ${ }^{\circledR}$ was distributed over round pieces of spiked paper 5 with $4.88 \mathrm{~cm}$ of diameter $\left(18.7 \mathrm{~cm}^{2}, \sim 0.3 \mathrm{~g}\right)$ and placed in covered Petri dishes. The amount of Tenax ${ }^{\circledR}$ per surface area of sample was ca $5 \mathrm{~g} / \mathrm{dm}^{2}$, not very different from the value

Table 3

Physical characteristics of the migrants with different chemical functionality.

\begin{tabular}{|c|c|c|c|c|c|c|}
\hline Name & $\mathrm{N}^{\circ}$ CAS & Mw & $\mathrm{Bp},{ }^{\circ} \mathrm{C}$ & $\log P o / w$ & $\begin{array}{l}\mathrm{Pv}, \mathrm{KPa} \\
\left(20^{\circ} \mathrm{C}\right)\end{array}$ & Structure \\
\hline Octane C8 & $111-65-9$ & 114 & 123 & $4.00-5.18$ & 1.4 & \\
\hline $\begin{array}{l}\text { Naphthalene } \\
\text { C6C4 }\end{array}$ & $91-20-3$ & 128 & 218 & 3.3 & $<0.01$ & \\
\hline Xylene C6-C-C & $95-47-6$ & 106 & 144 & 3.12 & 0.74 & \\
\hline $\begin{array}{l}\text { Methyl caproate } \\
\text { C5-COO-C }\end{array}$ & $106-70-7$ & 130 & 148 & & & \\
\hline $\begin{array}{l}\text { Di-iso-butyl ketone } \\
\quad \mathrm{C} 4 \mathrm{C}=\mathrm{OC} 4)\end{array}$ & $108-83-8$ & 142 & 169 & & 0.23 & \\
\hline $\begin{array}{l}\text { Acetophenone } \\
\qquad \mathrm{C} 6-\mathrm{C}=\mathrm{O}-\mathrm{C}\end{array}$ & $98-86-2$ & 120 & 202 & 1.58 & 0.06 & \\
\hline Octanal $\mathrm{C} 8=\mathrm{O}$ & $124-13-0$ & 128 & 171 & & 0.27 & \\
\hline $\begin{array}{l}\text { Benzyl alcohol } \\
\text { C6-C-OH }\end{array}$ & $100-51-6$ & 108 & 205 & 1.1 & 0.013 & \\
\hline $\begin{array}{l}\text { 2-Ethyl-1-hexanol } \\
\text { C8-OH }\end{array}$ & $104-76-7$ & 130 & 183 & & 0.05 & \\
\hline
\end{tabular}


recommended in standard EN 1186-13 $\left(4 \mathrm{~g} / \mathrm{dm}^{2}\right)$. The dishes were wrapped in aluminium foil to minimize losses, and stored. Three temperatures were tested in the phthalates experiment: $40^{\circ} \mathrm{C}$, $23{ }^{\circ} \mathrm{C}$ and $8{ }^{\circ} \mathrm{C}$ and 3 dishes were prepared for each of the 5 sampling periods from 0 to $200 \mathrm{~h}$. The experiment with the other migrants was conducted at $23^{\circ} \mathrm{C}$. 2 dishes were prepared for each of the 6 sampling periods from 0 to $150 \mathrm{~h}$. At each sampling time the dishes were removed and the Tenax ${ }^{\circledR}$ analysed for the migrants concentration. The paper replicates of the last sampling period were also analysed to verify the mass balance.

\subsection{Determination of partition coefficients between paper and $\operatorname{Tenax}^{\circledR} K_{P}^{T}$}

Paper pieces (in triplicate) with approximate dimensions of $2 \times 5 \mathrm{~cm}$ were brought in contact with $\operatorname{Tenax}^{\circledR}(0.15 \mathrm{~g})$ in $22 \mathrm{ml}$ vials. $1 \mu \mathrm{l}$ of spiking solution with phthalate DBP was added with care directly at the bottom of the vials in order to avoid the direct contact of the solution with the paper or with the Tenax ${ }^{\circledR}$. The vial was kept laid down in order to maintain the Tenax ${ }^{\circledR}$ on top of the paper and the set was allowed to equilibrate during 10 days at $23^{\circ} \mathrm{C}$. After equilibration the paper and the Tenax ${ }^{\circledR}$ were separated and the phthalate (DBP) concentration determined by gas-chromatography with mass spectra detection (GC-MS) in each matrix.

Two sets of experiments were carried out:

- At $23^{\circ} \mathrm{C}$, to study the influence of grammage and recycled pulp in the partition coefficient: papers 1, 2, 3 and 4 (Table 1) were spiked with a $5000 \mathrm{ppm}$ solution;

- At $40{ }^{\circ} \mathrm{C}$, to study the influence of different spiking concentrations: paper 3 was spiked with solutions 5000, 7500 and 10,000 ppm concentration in DBP.

\subsection{Determination of phthalates (kinetics experiment)}

Phthalates were determined after extraction from the paper or from the Tenax ${ }^{\circledR}$. A calibration curve with 5 calibration standard solutions was prepared and deuterated DHP (d-DHP) was used as internal standard. Standard solutions were injected in duplicate. The paper was cut in pieces and extracted with $10 \mathrm{ml}$ of a solution of d-DHP in hexane $(2 \mathrm{mg} / \mathrm{l})$ during $1 \mathrm{~h}$ under agitation and at ambient temperature. The extracts were analysed by GC-MS in duplicate. The Tenax ${ }^{\circledR}$ was extracted with $2 \times 7 \mathrm{ml}$ of hexane after addition of internal standard ( $0.2 \mathrm{ml}$ of d-DHP in hexane at $100 \mathrm{mg} /$ 1). The hexane was added, the solution stirred for $30 \mathrm{~s}$, left for $5 \mathrm{~min}$, filtered and collected into a $10 \mathrm{ml}$ volumetric flask (Tenax ${ }^{\circledR}$ absorbed a considerable amount of hexane). The procedure was repeated with other $7 \mathrm{ml}$ of hexane and the final flask volume was set. The extracts were analysed by GC-MS in duplicate.

\subsection{Determination of other migrants (kinetics experiment)}

Migrants were determined after extraction from the paper or from the Tenax ${ }^{\circledR}$. A calibration curve with 5 calibration standard solutions was prepared and BHT was used as internal standard. Standard solutions were injected in duplicate. The paper was cut in pieces and extracted with $5 \mathrm{ml}$ of a solution of BHT in hexane ( $2 \mathrm{mg} /$ 1) during $1 \mathrm{~h}$ under agitation and at ambient temperature. The extracts were analysed by GC-MS in duplicate. The Tenax ${ }^{\circledR}$ was extracted with $2 \times 7 \mathrm{ml}$ of hexane after addition of internal standard $(0.2 \mathrm{ml}$ of BHT in hexane at $100 \mathrm{mg} / \mathrm{l})$. The hexane was added, the solution stirred for $30 \mathrm{~s}$, left for $5 \mathrm{~min}$, filtered and collected into a $10 \mathrm{ml}$ volumetric flask (Tenax ${ }^{\circledR}$ absorbed a considerable amount of hexane). The procedure was repeated with other $7 \mathrm{ml}$ of hexane and the final flask volume was set. The extracts were analysed by GC-MS in duplicate.

\subsection{Determination of phthalate content}

In the paper: the paper was cut in pieces and extracted with $5 \mathrm{ml}$ of hexane plus $1 \mu \mathrm{l}$ of internal standard for $10 \mathrm{~min}$ under agitation at ambient temperature. The extracts were analysed by GC-MS in duplicate.

In the Tenax ${ }^{\circledR}$ : the Tenax $^{\circledR}$ was extracted with $5 \mathrm{ml}$ of hexane plus $1 \mu \mathrm{l}$ of internal standard for 10 min under agitation at ambient temperature. The extracts were analysed by GC-MS in duplicate.

\subsection{Chromatographic conditions}

Phthalates quantification:

Chromatograph Varian CP-3800 with detector MS (Ionisation mode: electronic impact $70 \mathrm{eV}$; Scan mode $\operatorname{SIM~}(\mathrm{m} / z 153$ ion $-\mathrm{d}$ DHP, $m / z 163$ ion - DMP and $m / z 149$ ion - other phthalates)

Column: VF-5MS $(30 \mathrm{~m} \times 0.25 \mathrm{~mm}, 0.25 \mu \mathrm{m})$

Temperature of the injector: $300{ }^{\circ} \mathrm{C}$

Oven: $50^{\circ} \mathrm{C}$ during $1 \mathrm{~min} ; 20^{\circ} \mathrm{C} / \mathrm{min}$ up to $150{ }^{\circ} \mathrm{C}$ and $10^{\circ} \mathrm{C} / \mathrm{min}$ up to $300^{\circ} \mathrm{C}$ during $1 \mathrm{~min}$

Volume of injection: $1 \mu \mathrm{l}$ split 1:10

\section{Other migrants quantification}

Chromatograph Varian CP-3800 with detector MS (Ionisation mode: electronic impact $70 \mathrm{eV}$; Scan mode SIM $(\mathrm{m} / z$ 43 ion octane, $m / z 91$ ion - xylene, $m / z 74$ ion - methyl caproate, $m / z$ 57 ion - diisobutyl ketone, $m / z 43$ ion - octanal, $m / z 57$ ion ethyl hexanol, $m / z 79$ ion - benzyl alcohol, $m / z 105$ ion - acetophenone, $m / z 128$ ion - naphthalene and $m / z 205$ ion - BHT) Column: VF-5MS $(30 \mathrm{~m} \times 0.25 \mathrm{~mm}, 0.25 \mu \mathrm{m})$

Temperature of the injector: $280^{\circ} \mathrm{C}$

Oven: $40{ }^{\circ} \mathrm{C}$ during $7 \mathrm{~min} ; 3^{\circ} \mathrm{C} / \mathrm{min}$ up to $100{ }^{\circ} \mathrm{C}$ for $1 \mathrm{~min}$ and $20^{\circ} \mathrm{C} / \mathrm{min}$ up to $160{ }^{\circ} \mathrm{C}$ for $2 \mathrm{~min} ; 20^{\circ} \mathrm{C} / \mathrm{min}$ up to $240{ }^{\circ} \mathrm{C}$ for $1 \mathrm{~min}$

Volume of injection: $2 \mu \mathrm{l}$ split:splitless (splitless time $0.5 \mathrm{~min}$ )

\subsection{Statistics and estimation of model parameters}

The software Statistica (StatSoft, Inc., Tulsa) was used to estimate the coefficients of the Weibull model $\tau$ and $\beta$ by non-linear estimation and least squares as loss function. The diffusion coefficients of the phthalates were estimated using the Office Excel 2003 function Solver (Microsoft Co.), considering fifteen terms for the summations in equation (1).

\section{Results and discussion}

\subsection{Analysis of phthalates migration using the Weibull model}

Migration from paper occurred very fast when compared to migration from plastics in general and scattering of data between replicates was also much higher. The migration results are presented as the relative migration over time, defined as the ratio of concentration of phthalates in the Tenax ${ }^{\circledR}$ to the initial concentration in the paper. The Weibull kinetic model was fit to the experimental data. The values of the model parameters and determination coefficients are presented in Table 4. The values of $\tau$ are relatively low, indicative of the high initial rate of the process. Values found for $\beta$ ranged from 0.5 to 1.5 . The shape of the migration curves is well represented by the Weibull model, not only for the phthalates with lower molecular weights showing 
Table 4

Estimates of Weibull model $(\mu \pm \epsilon)$.

\begin{tabular}{|c|c|c|c|c|c|c|}
\hline & & DMP & DEP & DBP & DHP & DOP \\
\hline \multirow[t]{4}{*}{$8^{\circ} \mathrm{C}$} & $C_{f}^{T} / C_{o}^{P}$ & 0.081 & $0.126 \pm 0.012$ & $0.152 \pm 0.014$ & $0.046 \pm 0.006$ & $0.013 \pm 0.001$ \\
\hline & $\tau, \mathrm{hr}$ & $38.5 \pm 7.8$ & $11.4 \pm 5.0$ & $20.8 \pm 6.7$ & $67.6 \pm 19.0$ & $86.0 \pm 11.0$ \\
\hline & $\beta$ & $0.65 \pm 0.15$ & $0.72 \pm 0.36$ & $0.88 \pm 0.30$ & $1.02 \pm 0.24$ & $1.04 \pm 0.32$ \\
\hline & $R^{2}$ & 0.792 & 0.700 & 0.783 & 0.917 & 0.811 \\
\hline \multirow[t]{4}{*}{$23^{\circ} \mathrm{C}$} & $C_{f}^{T} / C_{o}^{P}$ & 0.052 & 0.093 & $0.184 \pm 0.020$ & $0.098 \pm 0.010$ & $0.018 \pm 0.003$ \\
\hline & $\tau, \mathrm{hr}$ & $26.1 \pm 4.6$ & $40.9 \pm 7.6$ & $49.6 \pm 10.5$ & $52.5 \pm 8.4$ & $78.5 \pm 18.4$ \\
\hline & $\beta$ & $0.54 \pm 0.11$ & $0.64 \pm 0.13$ & $1.35 \pm 0.32$ & 1.50 & 1.50 \\
\hline & $R^{2}$ & 0.837 & 0.806 & 0.904 & 0.901 & 0.884 \\
\hline \multirow[t]{4}{*}{$40^{\circ} \mathrm{C}$} & $C_{f}^{T} / C_{o}^{P}$ & 0.036 & $0.057 \pm 0.003$ & $0.127 \pm 0.008$ & $0.114 \pm 0.009$ & $0.053 \pm 0.017$ \\
\hline & $\tau, \mathrm{hr}$ & 1.0 & $1.7 \pm 5.0$ & $11.9 \pm 2.1$ & $24.9 \pm 5.2$ & $80.4 \pm 41.7$ \\
\hline & $\beta$ & 0.5 & $0.53 \pm 0.95$ & $0.92 \pm 0.21$ & $1.22 \pm 0.15$ & $1.12 \pm 0.22$ \\
\hline & $R^{2}$ & & 0.584 & 0.918 & 0.955 & 0.939 \\
\hline
\end{tabular}

(*) Statistically not different from 0 .

a typical migration curve shape, but also for the heavier phthalate (DOP) which presented a sigmoidal migration curve. This atypical shape may be due to the evaporation process becoming the rate determining step (Fig. 2). The migration at $40{ }^{\circ} \mathrm{C}$ was very fast for the lighter phthalates (DMP and DEP) and the process was therefore basically controlled by the thermodynamic partition rather than by the kinetics of the transfer. Fig. 2 shows that the sometimes low values of $R^{2}$ were due to a high experimental error (deviation between replicates), and not to a model pattern different from that of data.

The values obtained for the $\tau$ and $\beta$ parameters of the Weibull model and for the relative migration were analysed in relation to the size of the alkyl chain of the phthalates $\left(\mathrm{CH}_{n}\right)$ and the respective boiling point. Theses results are plotted in Fig. 3.
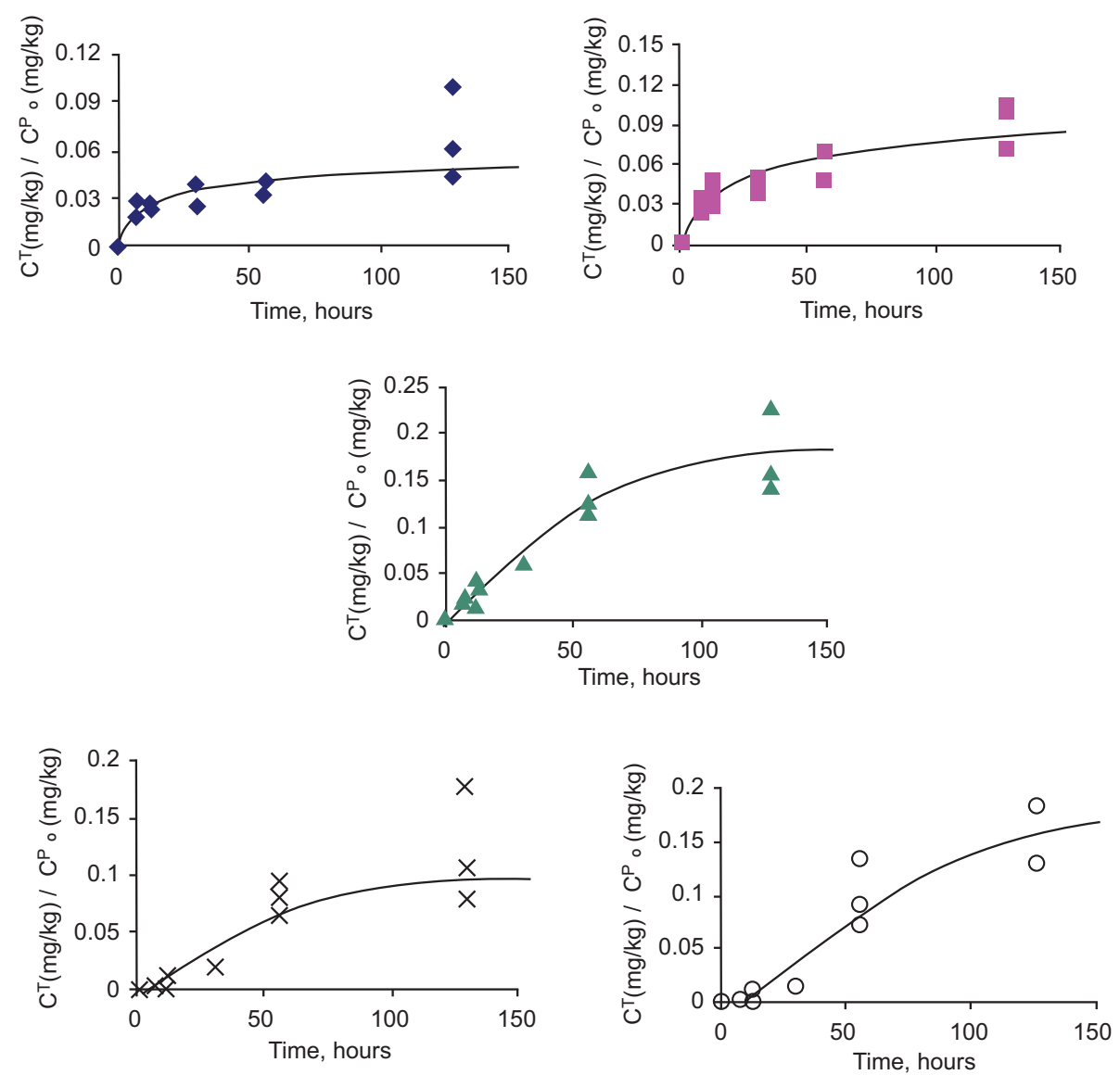

Fig. 2. Migration of phthalates into Tenax ${ }^{\circledR}$ at $23^{\circ} \mathrm{C}$ (three replicates): DMP 

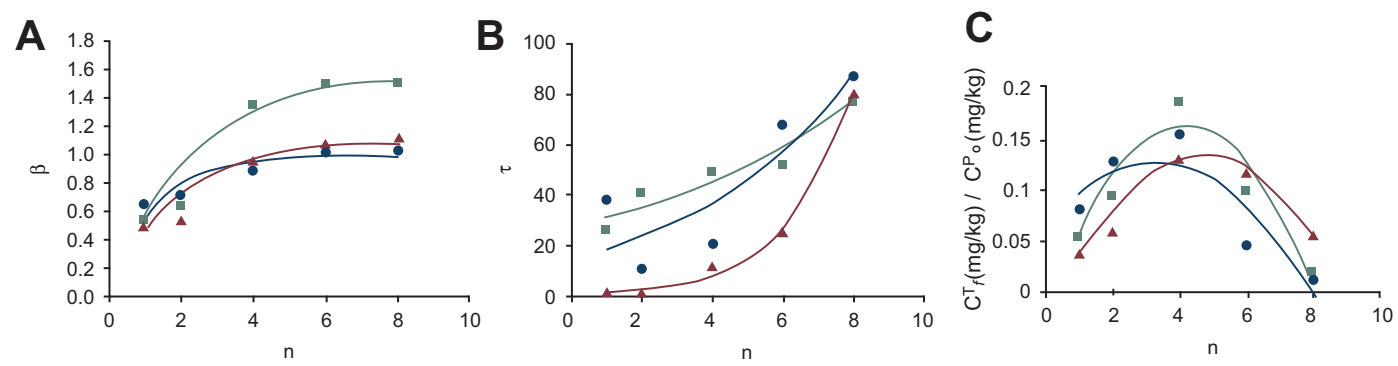

Fig. 3. Weibull parameters for different number of methyl groups in phthalates alkyl chain. A) $\beta ; \mathrm{B}) \tau ; \mathrm{C}) C_{F}^{T} / C_{0}^{P} ; 8{ }^{\circ} \mathrm{C}(\bullet) ; 23{ }^{\circ} \mathrm{C}(\boldsymbol{\square}) ; 40{ }^{\circ} \mathrm{C}(\boldsymbol{\Delta})$.

The parameter $\tau$ describes the rate of mass transfer and indicates that the higher the $n$ (or the boiling point), the lower the rate of migrant transfer from the paper to the Tenax ${ }^{\circledR}$ is (Fig. 3B). The behaviour can be described by a function of the type:

$\tau=a \cdot \exp (b \cdot n)$

$\tau$ increased substantially for high $n$ values, corresponding to no mass transfer, and it decreased to a plateau that appears to depend on the temperature, showing that the rate of transfer is less important in limiting the global process rate for the more volatile molecules. Fig. 4A presents the influence of temperature on the $\tau$ parameter. It is not possible to estimate the activation energy of the process because there is data available for only 3 temperatures and due to the high dispersion of the data the error would be too large. Nevertheless, in order to assist with the plot analyses, a linear trend line was drawn for each phthalate. The data suggest that, in the range studied, temperature has an impact on the rate of mass transfer of the more volatile phthalates and becomes less important for the heavier ones. Temperature seems to have no impact on the $\beta$ parameter as shown in Fig. 4B.

The final relative concentration showed lower values for the heaviest and for the lightest phthalates, presenting a maximum
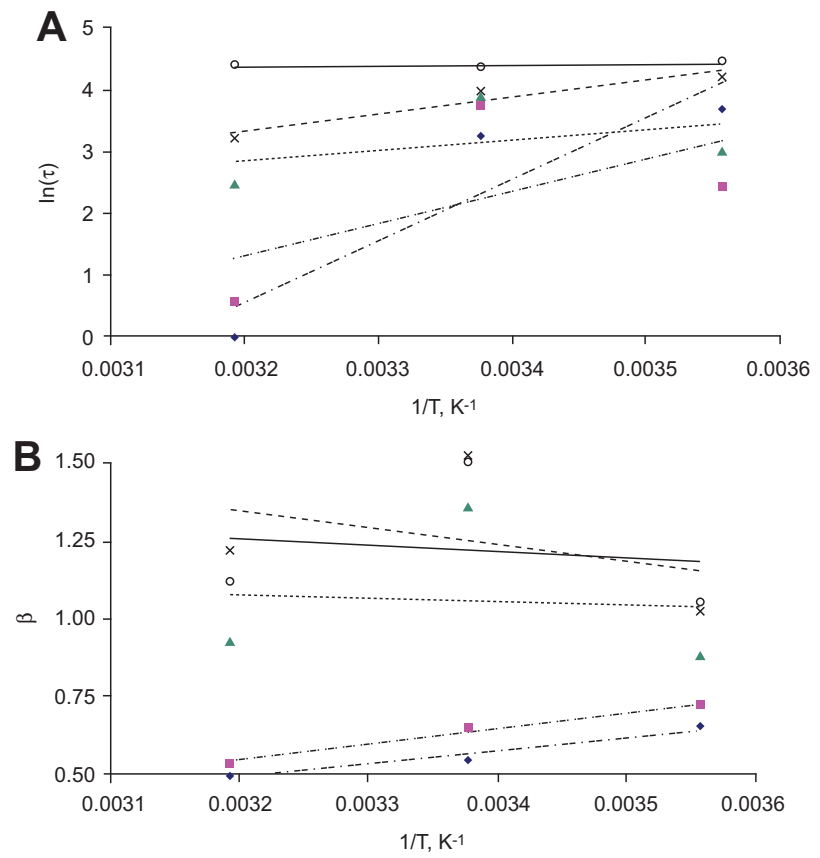

Fig. 4. Variation of the Weibull parameter with temperature in an Arrhenius plot: DMP (..-..); DEP (-.-); DBP (....); DHP (--); DOP (-); A) $\tau$; B) $\beta$. value for the medium size phthalates (Fig. 3C). This effect can be described by a 2 nd order polynomial function (8):

$\frac{C^{T} f}{C_{o}^{P}}=a+b(n)+c\left(n^{2}\right)$

This may be explained by two different aspects: on one hand DHP and DOP (molecules with higher boiling points), tend to migrate to a lesser extent due to their larger molecule size. On the other hand, the more volatile molecules, DMP and DEP, will evaporate to the surrounding air in greater proportion which results in higher losses from the system.

Losses from the system were quantified with the replicates of the last sampling time in each run. Losses were significant even at $8{ }^{\circ} \mathrm{C}$ for the DMP and DEP (Table 5). Results indicate that losses from the lighter phthalates are more sensitive to temperature than losses from the heavier phthalates and they decrease with boiling point. This can explain why the concentration found in the solid simulant for lighter phthalates and particularly at the higher temperature was lower than what would be expected in a complete closed system. These losses have also been reported by other authors (Castle, 2004; Nerín et al., 2007) and represent another important difference between migration from paper and from plastic. In a real package made of paper or paperboard these losses are also most likely to occur and therefore the system used may represent better the actual situation rather then a complete tight migration cell. However, for a complete understanding of the mass transfer process an experimental set up allowing for an independent study of the two contributing mechanisms would be most valuable.

Results of the fitting of data obtained at $23{ }^{\circ} \mathrm{C}$ with the solution of Fick's 2nd law are presented in Fig. 5. As can be seen this model described very well the results obtained for DMP and DEP, but was not able to describe adequately the results for the heavier phthalates that present a sigmoidal-shape. The diffusion coefficients were obtained by fitting the time dependent experimental data and results are presented in Table 6. According to the comparison between the Weibull and Fickian models presented in Poças et al. (in press), lower $\tau$ values correspond to higher diffusion coefficients as shown by the results. Results obtained for paper also show a fairly good relationship between $\tau$ and the ratio between the square of thickness of the material and the diffusion coefficient. Deterministic models based on the diffusion law described by equation (1) assume that all mass leaving the packaging material

Table 5

Losses (\%) from the migration cell during the kinetic experiment.

\begin{tabular}{llllll}
\hline & DMP & DEP & DBP & DHP & DOP \\
\hline $8{ }^{\circ} \mathrm{C}$ & 59 & 52 & 36 & 29 & 29 \\
$23{ }^{\circ} \mathrm{C}$ & 72 & 65 & 34 & 22 & 17 \\
$40^{\circ} \mathrm{C}$ & 85 & 76 & 40 & 24 & 34 \\
\hline
\end{tabular}


Table 6

Diffusion coefficient of phthalates in paper 5 at $23^{\circ} \mathrm{C}$.

\begin{tabular}{llllll}
\hline & DMP & DEP & DBP & DHP & DOP \\
\hline$D^{P}, \mathrm{~cm}^{2} / \mathrm{s}$ & $7.29 \mathrm{E}-10$ & $4.66 \mathrm{E}-10$ & $3.87 \mathrm{E}-10$ & $1.91 \mathrm{E}-10$ & $1.53 \mathrm{E}-11$ \\
\hline
\end{tabular}

enters the food and do not account for losses. As previously referred in the cases studied here, transfer occurs into the simulant but also out from the migration cell. Castle (2004) overcame this problem by expressing migration from paper as the fraction lost from the paper instead of using the concentration increase in the food simulant. Then the model traditionally used to describe migration from plastics (1), was applied. Although this transformation may be acceptable from a mathematical point of view, it is arguable from the fundamental point of view because in this case two parallel mass transfer processes are taking place: one from the paper into the food (that may potentially be described by Fick's law) and another from the paper to the surroundings (that may be described by Henry's law). It follows that having no physical reason to apply the diffusion model, the Weibull kinetic model reveals itself very interesting for this application because of its simplicity and capability of simulating behaviours which depend on the phthalate type.

\subsection{Migration of substances with different chemical character}

Fig. 6 presents the relationship between the migrant relative final concentration in the Tenax ${ }^{\circledR}$ and the respective boiling point obtained in the migration from the spiked paper with chemicals of

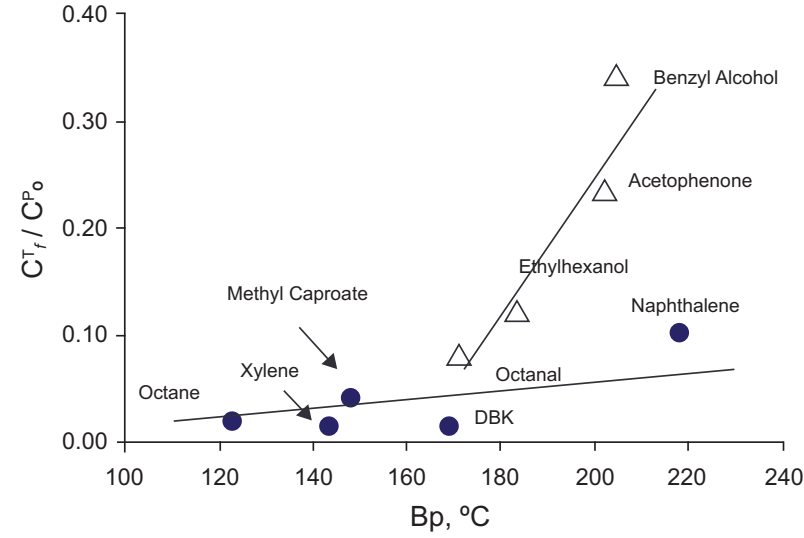

Fig. 6. Relative migrant concentration in Tenax ${ }^{\circledR}$ at final as a function of respective boiling point ( nonpolar or less polar; $\Delta$ polar or less unpolar).

different chemical nature at $23{ }^{\circ} \mathrm{C}$. Due to the migrant losses from the migration system, it is not possible to consider equilibrium concentrations but rather final concentrations $(t=120 \mathrm{~h})$. Two areas can be distinguished in the graph: the polar area corresponding to the migrants acetophenone, octanal, benzyl alcohol and ethyl hexanol and the nonpolar or medium polar area, with the migrants octane, xylene and DBK. The polar migrants have generally higher boiling points and present higher values of final concentration in the Tenax ${ }^{\circledR}$ than those observed for the nonpolar migrants. Polar migrants tend to have more affinity to the paper
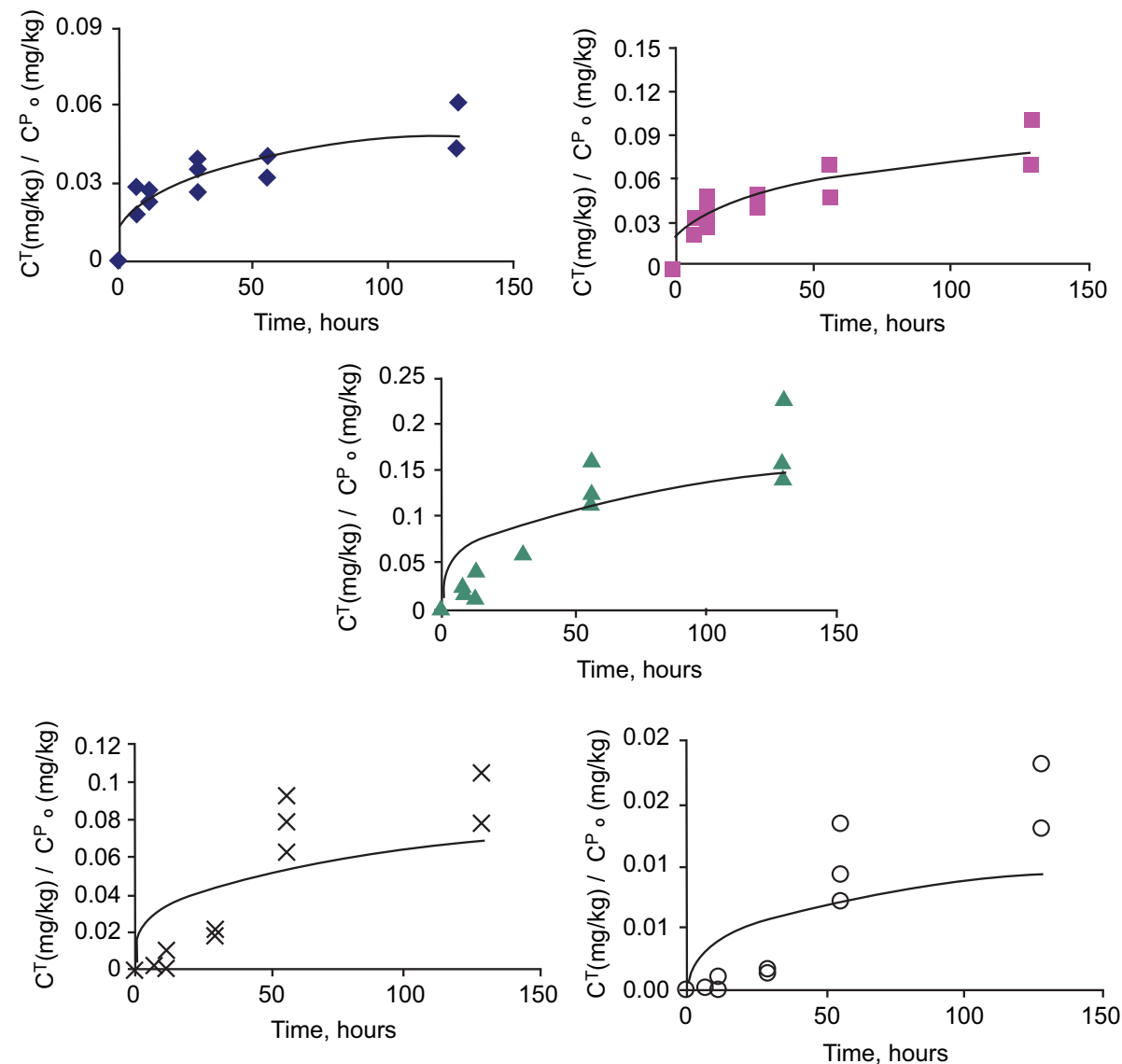

Fig. 5. Migration of phthalates into Tenax ${ }^{\circledR}$ at $23{ }^{\circ} \mathrm{C}$ (three replicates): DMP $(\bullet)$; DEP 
Table 7

Partition coefficients of different types of paper at $23^{\circ} \mathrm{C}(\mu \pm \sigma)$.

\begin{tabular}{lllll}
\hline Paper & 1 & 2 & 3 & 4 \\
\hline DBP & $0.036 \pm 0.021$ & $0.166 \pm 0.096$ & $0.165 \pm 0.073$ & $0.247 \pm 0.059$ \\
\hline
\end{tabular}

and are less volatile; therefore their transfer is highly dependent on the vapour pressure. Furthermore, their losses from the system are lower, yielding higher relative concentration after $150 \mathrm{~h}$ at $23^{\circ} \mathrm{C}$. In the nonpolar region, much lower levels of concentration of the migrant in the simulant are observed, due to the higher losses, and in this range the boiling point does not affect the level of migration so markedly as in the other region. The lower boiling points (higher values of vapour pressure) and relatively less affinity to the paper matrix promote volatilization. The high level of losses from the system may explain these lower final values. Naphthalene presents a distinct behaviour because it has a high boiling point but it also presents a nonpolar character. It shows an intermediate behaviour of relative migration into Tenax ${ }^{\circledR}$.

\subsection{Partition behaviour between paper and Tenax ${ }^{\circledR}$}

The results obtained for the partition coefficient of DBP $\left(K_{P}^{T}\right)$ between the different papers and Tenax ${ }^{\circledR}$ are presented in Table 7.

The analysis of variance (ANOVA) showed that both paper grammage and recycled pulp have a mean effect $(\sim 30 \%)$ on the partition coefficient. However these mean effects are of the same order of magnitude of the error due to the high variability of the results obtained between replicates for each type of paper. Results indicate that there is no interaction effect between these two factors. This leads to the conclusion that generally an increase in paper grammage yields higher partition coefficients, i.e. higher concentrations in the paper relative to the concentration in the Tenax ${ }^{\circledR}$. This could be expected because the migrant is adsorbed in specific sites of the paper fibres. Therefore, the migrant uptake by paper is limited by the paper adsorption capacity, which depends on the thickness or grammage. The same conclusion can be drawn for the recycled pulp content.

The influence of the concentration of the spiking solution on the partition coefficient is presented in Fig. 7. There is a decreasing trend of the $K_{P}^{T}$ with the concentration, however, given the high error between replicates, the influence is of the same order of magnitude of the error itself. Depending on the chemical nature of the migrant influencing the interaction between its functional groups and paper's, it may be reasonably expected that concentration influences the partition coefficients.

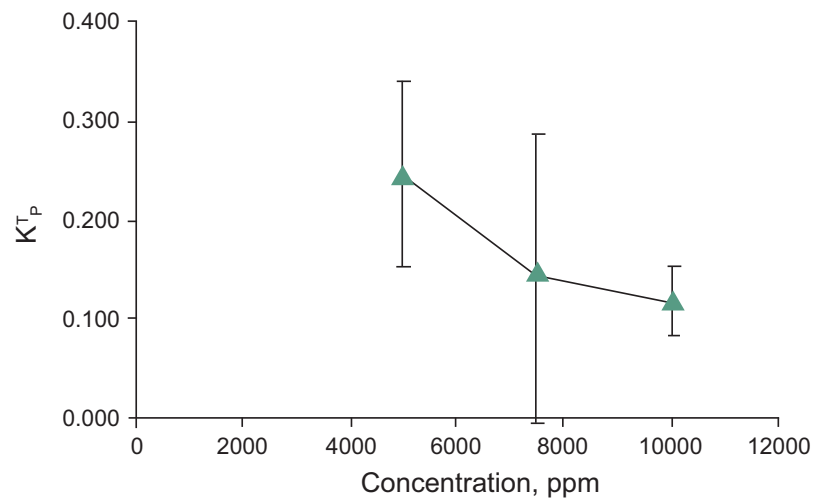

Fig. 7. Partition coefficient of DBP between paper 3 and Tenax ${ }^{\circledR}$ at different concentrations; average of three replicates \pm standard deviation.

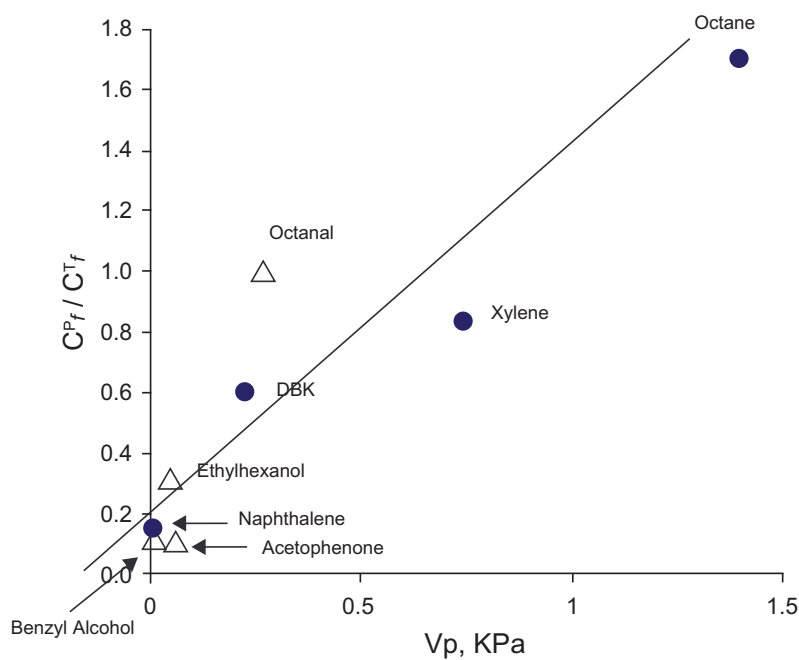

Fig. 8. Ratio of migrants concentration in paper to Tenax ${ }^{\circledR}$ as a function of respective vapour pressure ( nonpolar or less polar; $\Delta$ polar or less unpolar).

The ratio of migrant concentration in the paper sample 5 and the concentration in the Tenax ${ }^{\circledR}$, at the end of the migration time, was calculated for the migrants with different chemical functionalities. These ratios are not true partition coefficients because loss of migrants occurred, as explained before, and therefore, there was no real equilibrium. Notwithstanding, the ratios (apparent partition coefficients) are a good indication of the partition behaviour of the substances and are represented as a function of the vapour pressure in Fig. 8. Results show that migrants with higher vapour pressure have a higher $C_{f}^{P} / C_{f}^{T}$.

\section{Conclusions}

Migration from paper is a much faster process compared to migration from plastics, and involves transfer into the food and, simultaneously, transfer into the atmosphere surrounding the packages. Volatility and polarity of the migrants determine their migration to the food simulant, but also the losses from the system due to evaporation. From the phthalates series tested, DBP tends to migrate into Tenax ${ }^{\circledR}$ in greater extent because of its medium volatility. The rate of migration of phthalates decreases and becomes less dependent on temperature with increasing molecular weight. The rate of migration of substances with different chemical functionalities was not estimated due to the unexpected behaviour for earlier migration times, possibly due to the high losses from the migration cell. The final relative concentration in the Tenax ${ }^{\circledR}$ seems to be greatly determined by polarity. Nonpolar substances equilibrate at relative low levels in the simulant and the level is not very influenced by the substance boiling point or vapour pressure, while polar substances equilibrate at higher relative concentration which depended highly on the substance vapour pressure.

Mass transfer from paper to Tenax ${ }^{\circledR}$ cannot be adequately described by diffusion models in many cases, and the empirical Weibull model represents a good alternative. The Weibull model describes very well the migration of the phthalates series. The shape parameter $\beta$ increased with the size of phthalate up to ca 1.5 and it did not depend on temperature. The rate parameter $\tau$ (system time constant) increased asymptotically with the size of phthalate. $\tau$ depended on temperature for the lighter phthalates only. The rate of transfer of heavier phthalates was not affected significantly by temperature in the range considered. This simple model is able to describe the pattern of migration curves for a wide range of migrant 
volatility. The relationships to derive the model parameters are promising but need further data for validation and expansion to other substances.

\section{References}

Anderson, W. A. C., \& Castle, L. (2003). Benzophenone in cartonboard packaging materials and the factors that influence its migration into food. Food Additives $\mathcal{G}$ Contaminants, 20(6), 607-618.

Aurela, B., \& Ketoja, J. A. (2002). Diffusion of volatile compounds in fibre networks: experiments and modelling by random walk simulation. Food Additives $\mathcal{\sigma}$ Contaminants, 19(4 S. 1), 56-62.

Aurela, B., Kulmala, H., \& Soderhjelm, L. (1999). Phthalates in paper and board packaging and their migration into Tenax and sugar. Food Additives $\mathcal{E}^{\prime}$ Contaminants, 16(12), 571-577.

Bradley, E. L., Castle, L., Dines, T. J., Fitzgerald, A. G., Tunon, P. G., Jickells, S. M., et al. (2005). Test method for measuring non-visible set-off from inks and lacquers on the food-contact surface of printed packaging materials. Food Additives $\mathcal{E}$ Contaminants, 22(5), 490-502.

Castle, L. (2004). Migration from recycled paper and board to dry foods. Research into the factors involved, leading to practical avoidance and amelioration measures. Report FD 04/07. York: CSL.

Choi, J., Jitsunari, F., Asakawa, F., \& sun Lee, D. (2005). Migration of styrene monomer, dimers and trimers from polystyrene to food simulants. Food Additives $\mathcal{E}$ Contaminants, 22(7), 693-699.

García-Gómez, C., Carbonell, G., \& Tarazona, J. V. (2004). Modelling the absorption and desorption of cadmium on paper pulp using kinetic approaches. Chemosphere, 55(6), 869-878.

Haack, G., Franz, R. (2000). Partition coefficients of volatile substances between coated or non-coated cardboard and air as a basis for the estimation of migration from packaging into food. Poster at the 2nd ILSI International Symposium on Food Packaging, Vienna, Austria, 8-10 November.

Hellén, E. K. O., Ketoja, J. K., Niskanen, K. J., \& Alava, M. J. (2002). Diffusion through fibre networks. Journal of Pulp and Paper Science, 28(2), 55-62.

Jickells, S. M., Poulin, J., Mountfort, K. A., \& Fernàndez-Ocaña, M. (2005). Migration of contaminants by gas phase transfer from carton board and corrugated board box secondary packaging into foods. Food Additives E Contaminants, 22(8), 768-782.
Johns, S. M., Jickells, S. M., Read, W. A., Gramshaw, J. W., \& Castle, L. (1996). Studies on functional barriers to migration. Use of model substances to investigate transfer from paper and board packaging to food. Deutsche Lebensmittel Rundschau, 92, 273-278.

Mariani, M. B., Chiacchierini, E., \& Gesumundo, C. (1999). Potential migration of diisopropyl naphthalenes from recycled paperboard packaging into dry foods. Food Additives \& Contaminants, 16(5), 207-213.

Nerín, C., \& Acosta, D. (2002). Behaviour of some solid food simulants in contact with several plastics used in microwave ovens. Journal of Agricultural and Food Chemistry, 50, 7488-7492.

Nerín, C., Contín, E., \& Asensio, E. (2007). Kinetic migration studies using Poropak as solid-food simulant to assess the safety of paper and board as food packaging materials. Analytical and Bioanalytical Chemistry, 387, 2283-2288.

Poças, M. F., Oliveira, J. C., Brandsch, R., Hogg, T. Analysis of mathematical models to describe the migration of additives from packaging plastics to foods. Journal of Food Engineering, in press.

Poças, M. F. F., \& Hogg, T. (2007). Exposure assessment of chemicals from packaging materials in foods: a review. Trends in Food Science E Technology, 18 219-230.

Song, Y. S., Begley, T., Paquette, K., \& Komolprasert, V. (2003). Effectiveness of polypropylene film as a barrier to migration from recycled paperboard packaging to fatty and high-moisture food. Food Additives $\mathcal{E}$ Contaminants, 20(9) $875-883$.

Summerfield, W., \& Cooper, I. (2001). Investigation of migration from paper and board into food-development of methods for rapid testing. Food Additives $\mathcal{E}$ Contaminants, 18(1), 77-88.

Triantafyllou, V. I., Akrida-Demertzi, K., \& Demertzis, P. G. (2007). A study on the migration of organic pollutants from recycled paperboard packaging materials to solid food matrices. Food Chemistry, 101(4), 1759-1768.

Triantafyllou, V. I., Akrida-Demertzi, K., \& Demertzis, P. G. (2005). Determination of partition behaviour of organic surrogates between paperboard packaging materials and air. Journal of Chromatography A, 1077(1), 74-79.

Triantafyllou, V. I., Akrida-Demertzi, K., \& Demertzis, P. G. (2002). Migration studies from recycled paper packaging materials: development of an analytical method for rapid testing. Analytica Chimica Acta, 467, 253-260.

Zhang, K., Noonan, G. O., \& Begley, T. H. (2008). Determination of 2,6-diisopropylnaphthalene (DIPN) and n-dibutylphthalate (DBP) in food and paper packaging materials from US marketplaces. Food Additives $\mathcal{E}$ Contaminants, 25(11) 1416-1423 